\title{
Predictive Ability of C-Reactive Protein in Detecting Short-Term Complications After Cytoreductive Surgery and Hyperthermic Intraperitoneal Chemotherapy: A Retrospective Cross-Sectional Study
}

\author{
Job P. van Kooten, MD ${ }^{1}$, Arvind Oemrawsingh, MD, MHS ${ }^{1}$, Nadine L. de Boer, MD $^{1}$, Cornelis Verhoef, MD, PhD $^{1}$, \\ Jacobus W. A. Burger, MD, PhD ${ }^{1,2}$, Eva V. E. Madsen, MD, PhD ${ }^{1}$, and Alexandra R. M. Brandt-Kerkhof, MD $^{1}$ \\ ${ }^{1}$ Department of Surgical Oncology, Erasmus MC Cancer Centre, Rotterdam, The Netherlands; ${ }^{2}$ Department of Surgery, \\ Catharina Hospital, Eindhoven, The Netherlands
}

\begin{abstract}
Background. Cytoreductive surgery (CRS) with hyperthermic intraperitoneal chemotherapy (HIPEC) is a potentially curative treatment for peritoneal carcinomatosis.

Objective. The aim of this study was to determine the predictive value of postoperative inflammatory biomarkers in assessing complications after CRS and HIPEC.

Methods. A prospective database of 181 patients, who underwent CRS-HIPEC between March 2014 through April 2018 in the Erasmus MC, was retrospectively analyzed. Postoperative complications were defined according to the serious adverse event (SAE) grading system. Levels of C-reactive protein (CRP) and white blood cell (WBC) count were compared between patients with SAE grade $<3$ and $\mathrm{SAE}$ grade $\geq 3$. The area under the receiver operating characteristic curve (AUC) was calculated for $\mathrm{CRP}$ and $\mathrm{WBC}$ against $\mathrm{SAE} \geq 3$ and various intra-abdominal complications.
\end{abstract}

Results. SAE $\geq 3$ postoperative complications occurred in 50 patients. From the second until the fifth postoperative day (POD), CRP levels were significantly higher

Job P. van Kooten and Arvind Oemrawsingh shared co-first authorship.

(C) The Author(s) 2020

First Received: 1 August 2019;

Published Online: 10 June 2020

A. R. M. Brandt-Kerkhof, MD

e-mail: a.brandt-kerkhof@erasmusmc.nl
( $p=0.023, p<0.001, p=0.002$, and $p=0.002$, respectively) in these patients. CRP concentrations above $166 \mathrm{mg} / \mathrm{L}$ on POD3 (AUC 0.75) and $116 \mathrm{mg} / \mathrm{L}$ on POD4 (AUC 0.70) were associated with the highest risk of an $\mathrm{SAE} \geq 3$. Postoperative WBC levels were not significantly different between patients with $\mathrm{SAE}<3$ and $\mathrm{SAE} \geq 3$ complications.

Conclusion. Data from our hospital suggest that CRP levels that continue to rise after POD2 or that are $\geq 166 \mathrm{mg} / \mathrm{L}$ at POD3 or $\geq 116 \mathrm{mg} / \mathrm{L}$ at POD4, indicate a considerable risk for developing high-grade SAEs. The cutoff values we found can potentially be used as a threshold for additional diagnostic interventions, after they have been validated in external data.

Cytoreductive surgery combined with intraoperative hyperthermic intraperitoneal chemotherapy (CRS-HIPEC) has been considered a potentially curative therapeutic modality for patients presenting with peritoneal carcinomatosis (PC). ${ }^{1-3}$ This extensive surgical treatment has been associated with improved survival outcomes for selected patients with PC from colorectal cancer (CRC) and pseudomyxoma peritonei (PMP), with 5-year survival rates of approximately $30 \%$ and $74 \%$ for CRC and PMP, respectively. $^{4-6}$ However, it has also been associated with considerable postoperative morbidity and mortality, with estimates of approximately $30 \%$ and 2-3\%, respectively. $^{7-9}$ When attempting to reduce postoperative morbidity and mortality, early recognition of high-grade serious adverse events (SAEs) could be of great significance. 
C-reactive protein (CRP) is an acute-phase inflammation protein secreted primarily by liver hepatocytes, smooth muscle cells, and adipocytes, among others. ${ }^{10}$ With its halflife being only $19 \mathrm{~h}$ and its increase being proportional to the degree of the inflammation process, CRP has established itself as an inexpensive, highly sensitive but nonspecific biomarker of systemic inflammatory response, ${ }^{11,12}$ and has been identified as a potential predictive marker of postoperative complications after abdominal surgery. ${ }^{13,14}$ Intra-abdominal complications, mainly septic complications or anastomotic leakage, are associated with mortality, reoperation, increased hospital stay, and higher costs. ${ }^{15}$

Research on the utility and predictive value of biomarkers, such as CRP and WBC (white blood cell) levels, after CRS and HIPEC has been limited. ${ }^{16}$ The aim of this cross-sectional retrospective study was to determine the predictive value of postoperative CRP and WBC levels in identifying complications after CRS and HIPEC in patients with PC from CRC or PMP.

\section{METHODS}

\section{Study Population}

All patients with PC from CRC or PMP who underwent CRS-HIPEC in the Erasmus Medical Center between March 2014 through April 2018 were included in this study. A prospective database was built based on patients' chart review by using the electronic medical record system at this institution. Patients with recurrent peritoneal disease who underwent a second CRS-HIPEC procedure in the aforementioned time interval, were also included.

\section{Perioperative Course}

CRS-HIPEC procedures were performed by a specialized surgical team and in accordance with Dutch CRS and HIPEC protocols. ${ }^{17}$ After abdominal access via laparotomy, a thorough assessment of the extent of peritoneal disease (only in cases with PC from colorectal and appendiceal cancer) was conducted to determine the Peritoneal Cancer Index (PCI) score according to Jacquet and Sugarbaker. ${ }^{18}$ If the PCI score was under 20 and/or the specialized surgeons deemed the peritoneal disease resectable, the greater omentum, primary tumor (if still present), affected visceral abdominal organs, affected parietal surfaces, and all peritoneal implants were resected. Administration of HIPEC was by way of the open (coliseum) technique in which the abdominal cavity was filled with an iso-osmotic glucose/electrolyte dialysis (Dianeal ${ }^{\circledR}$ ) carrier solution, with either mitomycin-C or oxaliplatin being added to the perfusate as chemotherapeutic agent, once the desired abdominal temperature of $>40{ }^{\circ} \mathrm{C}$ was reached. After the HIPEC perfusion, intestinal bowel anastomoses and/or a stomy procedure was performed if necessary.

Postoperatively, patients were treated following standard of care for CRS-HIPEC procedures. Laboratory tests and diagnostic imaging modalities, such as computed tomography (CT) scans, were liberally used when deemed necessary. Postoperative complications were retrospectively classified according to the SAE grading system: $\mathrm{SAE}=1$ denotes an asymptomatic or mild complication (intervention not indicated); $\mathrm{SAE}=2$ denotes a moderate complication (local or non-invasive intervention indicated); $\mathrm{SAE}=3$ denotes a severe complication (significant but not immediately life-threatening, radiological or surgical intervention indicated); $\mathrm{SAE}=4$ denotes a lifethreatening complication (reoperation and/or prolonged intensive care unit [ICU] stay indicated); and $\mathrm{SAE}=5$ denotes in-hospital death related to the adverse event. ${ }^{17,19}$ Intra-abdominal gastrointestinal complications included anastomotic leakage, bowel perforation or ischemia/ necrosis. The postoperative period was defined as the duration of the entire hospital stay following CRS and HIPEC, regardless of length.

\section{Laboratory Data}

Laboratory results (including postoperative biomarkers) of all patients who underwent CRS-HIPEC were recorded on arrival to the ICU and then daily during the patient's usually brief stay (1-3 days). When transferred to the ward, CRP levels were drawn in addition to a complete blood count (CBC), including white blood cell (WBC) count and blood chemistry in patients, usually three times a week (according to the Erasmus MC CRS-HIPEC protocol). CRP and WBC levels were routinely measured on postoperative days (PODs) 1, 2, 3, 4, and/or 5. Laboratory data were gathered retrospectively.

\section{Statistical Analysis}

Quantitative variables are presented as median with interquartile range (IQR), while categorical variables are presented as counts with percentages. Daily postoperative CRP values and WBC count between the $\mathrm{SAE}<3$ and $\mathrm{SAE} \geq 3$ groups were compared using the Mann-Whitney U-test (non-parametric). All tests were performed twosided and results were considered significantly different when the $p$ value was $<0.05$. Diagnostic accuracy of CRP and WBC values on consecutive PODs was analyzed using the receiver operating characteristic (ROC) curve by calculating separate cut-off levels for CRP and WBC with optimal sensitivity and specificity. Outcomes assessed were 
intra-abdominal gastrointestinal complications, intra-abdominal abscess, and $\mathrm{SAE} \geq 3$. Areas under the receiver operating characteristic curves (AUCs) were used to compare ROC curves. Statistical analyses were performed using the Statistical Package for Social Sciences (SPSS) version 21.0 (IBM Corporation, Armonk, NY, USA).

\section{Ethical Considerations}

All study procedures were performed according to the Erasmus MC Research Codes and with permission of the local Medical Ethics Review Committee (MEC-20181286).

\section{RESULTS}

\section{Study Population}

From March 2014 to May 2018, 181 patients underwent CRS-HIPEC in the Erasmus Medical Center. Patient- and tumor-related characteristics are described in Table 1. Three patients underwent a re-HIPEC within the aforementioned time interval, bringing the total number of analyzed CRS-HIPEC procedures to 184 . Primary tumors included 147 colorectal adenocarcinomas (81.2\%), 22 PMPs (12.2\%), and 12 appendiceal adenocarcinomas $(6.6 \%)$. Comparison of the baseline characteristics showed that the $\mathrm{SAE} \geq 3$ group comprised significantly more male patients (67\% vs. $44 \% ; p=0.006)$. No further differences at baseline existed between groups.

\section{Intraoperative and Postoperative Course}

Table 2 reports the intraoperative course characteristics. Median procedure time of CRS-HIPEC was $398 \mathrm{~min}$ [327-475]. Of all patients with peritoneally disseminated CRC $(n=147)$, the median PCI was $10 .^{6-16}$ Bowel anastomosis was performed in 109 procedures $(59.2 \%)$, and median blood loss was $1183 \mathrm{~mL}$ [714-2075]. In the $\mathrm{SAE} \geq 3$ group, significantly more cholecystectomies were performed ( $16 \%$ vs. $3.7 \%$; $p=0.004)$. In addition, median intraoperative blood loss was significantly more in the $\mathrm{SAE} \geq 3$ group $(1533 \mathrm{~mL}$ [900-2700] vs. $1063 \mathrm{~mL}$ [688-1763]; $p=0.005)$. SAE score $\geq 3$ complications occurred after $50(27.2 \%)$ procedures (Table 3 ), of which $36 \%$ were gastrointestinal complications (anastomotic leakage and bowel perforation/ischemia). The most frequently occurring major complications in the cohort were intra-abdominal abscess (11.4\%), anastomotic leakage (4.9\%), intra-abdominal bleeding (3.8\%), and pulmonary embolisms (3.8\%). Reoperation had to be performed in 28
(15.2\%) patients. Median duration of hospital stay was 17 days. $^{13-23}$

\section{Postoperative Biomarkers}

The overall evolution of median CRP values up to POD 5 is shown in Fig. 1a. Overall, the median CRP value increased from $89.5 \mathrm{mg} / \mathrm{L}$ [67.3-126] (POD 1) to a peak of $136 \mathrm{mg} / \mathrm{L}$ [95-206] (POD 2), and then decreased to $113 \mathrm{mg} / \mathrm{L}$ [64-185] (POD 3). The proportion of missing data was $52.7 \%$ on POD 4, but surpassed $60 \%$ on PODs 5 and 6. In patients who developed an $\mathrm{SAE} \geq 3$ complication, the median CRP value increased from $92 \mathrm{mg} / \mathrm{L}$ [65.5-142.5] (POD 1) to 202.5 mg/L [102.3-282] (POD 3), and ultimately to $182 \mathrm{mg} / \mathrm{L}$ [71-276] (POD 5). Six (12\%) $\mathrm{SAE} \geq 3$ complications were diagnosed and treated by reoperation before POD 3, thus resulting in a deviated course of CRP levels on POD 3 and beyond. Of all SAE $\geq 3$ complications, four $(8 \%)$ were diagnosed and treated by reoperation between POD 3 and POD 5. In 39 (78\%) patients, $\mathrm{SAE} \geq 3$ complications were diagnosed after peak CRP concentration (POD 3), with a median of 8 days $^{5-10}$ following CRS-HIPEC. As can be seen in Fig. 1a, in cases of postoperative complications with SAE grade $<3$, CRP concentrations peaked on POD $2(127 \mathrm{mg} /$ $\mathrm{L})$, and also peaked at POD $3(205 \mathrm{mg} / \mathrm{L})$ in patients with $\mathrm{SAE} \geq 3$. Median CRP values were significantly higher between patients with $\mathrm{SAE} \geq 3$ versus patients with $\mathrm{SAE}<3$ on POD $2 \quad(173.5 \mathrm{mg} / \mathrm{L}$ vs. $127 \mathrm{mg} / \mathrm{L}$; $p=0.023)$, POD $3(202.5 \mathrm{mg} / \mathrm{L}$ vs. $104 \mathrm{mg} / \mathrm{L} ; p<0.001)$, POD $4(137 \mathrm{mg} / \mathrm{L}$ vs. $73.5 \mathrm{mg} / \mathrm{L} ; p=0.002)$, and POD 5 $(182 \mathrm{mg} / \mathrm{L}$ vs. $80.5 \mathrm{mg} / \mathrm{L} ; p=0.002)$.

No similar trends were observed for postoperative WBC levels (Fig. 1b). Overall, median WBC count on POD 1 was $13.4 * 10^{9} / \mathrm{L}$ [10.8-16.2], which declined steadily to $7.9 * 10^{9} / \mathrm{L}$ [5.6-10.7] on POD 5. WBC did not differ significantly on the first 5 PODs between patients who developed SAE grade $\geq 3$ complications versus patients who developed SAE grade $<3$ complications. However, in 18 patients who developed either anastomotic leakage, bowel ischemia, or perforation, median WBC levels first declined, from $14.7 * 10^{9} / \mathrm{L}[11.3-17.8]$ at $\mathrm{POD} 1$ to $11.0 * 10^{9} / \mathrm{L}$ [9.8-12.9] on POD 3, after which they rose to $12.6 * 10^{9} / \mathrm{L}[8.2-16.6]$ on POD $4(p=0.031)$.

\section{Predictive Value of Biomarkers}

Figure $2 \mathrm{a}, \mathrm{b}$ shows the ROC curves for $\mathrm{SAE} \geq 3$ against CRP values on PODs 3 (AUC 0.75, 95\% confidence interval [CI] 0.65-0.85; $p<0.001$ ) and 4 (AUC 0.70, 95\% CI $0.59-0.81 ; p=0.002$ ), respectively. On POD 3 , a cutoff CRP value of $166 \mathrm{mg} / \mathrm{L}$ had a sensitivity of $61.1 \%$ and a specificity of $84.5 \%$. On POD 4, sensitivity and 
TABLE 1 Baseline characteristics

\begin{tabular}{|c|c|c|c|c|}
\hline & $\begin{array}{l}\text { All patients } \\
{[N=181]}\end{array}$ & $\begin{array}{l}\mathrm{SAE}<3 \\
{[n=133]}\end{array}$ & $\begin{array}{l}\mathrm{SAE} \geq 3 \\
{[n=48]}\end{array}$ & $p$ value \\
\hline Female & $91(50.3)$ & $75(56.4)$ & $16(33.3)$ & 0.006 \\
\hline Age, years & $62[53-69]$ & $60[52-70]$ & $64[56.3-68.8]$ & NS \\
\hline BMI & 25.6 [22.8-29] & 25.4 [22.3-28.7] & 26.4 [24.1-29.4] & NS \\
\hline Smoking (past or current) & $88(48.6)$ & $60(45.1)$ & $28(58.3)$ & NS \\
\hline Diabetes & 21 (11.6) & $14(10.5)$ & 7 (14.6) & NS \\
\hline IDDM & $8(38)$ & $6(42.9)$ & $2(28.6)$ & NS \\
\hline Hypertension & $42(23.2)$ & $29(21.8)$ & $13(27.1)$ & NS \\
\hline ASA classification & & & & NS \\
\hline 1 & $34(18.8)$ & $28(21.1)$ & $6(12.5)$ & \\
\hline 2 & $115(63.5)$ & $84(63.2)$ & $31(64.6)$ & \\
\hline 3 & $32(17.7)$ & $21(15.8)$ & $11(22.9)$ & \\
\hline Primary tumor & & & & NS \\
\hline Appendix cancer & $12(6.6)$ & $8(6)$ & $4(8.3)$ & \\
\hline PMP & $22(12.2)$ & $15(11.3)$ & 7 (14.6) & \\
\hline CRC ascending colon & $60(33.1)$ & $47(35.3)$ & $13(27.1)$ & \\
\hline CRC transverse colon & $10(5.5)$ & $7(5.3)$ & $3(6.3)$ & \\
\hline CRC descending colon & $16(8.8)$ & $12(9.0)$ & $4(8.3)$ & \\
\hline CRC sigmoid & $39(21.5)$ & $29(21.8)$ & $10(20.8)$ & \\
\hline CRC rectum & $22(12.2)$ & $15(11.3)$ & $7(14.6)$ & \\
\hline PC diagnosis & & & & NS \\
\hline Synchronous & 88 (48.6) & 65 (48.9) & $23(47.9)$ & \\
\hline Metachronous & 93 (51.4) & $68(51.1)$ & $25(52.1)$ & \\
\hline
\end{tabular}

Continuous variables are reported as median [IQR], and proportions are reported as $n(\%)$

$S A E$ serious adverse event, $B M I$ body mass index, IDDM insulin-dependent diabetes mellitus, ASA America Society of Anesthesiologists, $P M P$ pseudomyxoma peritonei, $P C$ peritoneal carcinomatosis, IQR interquartile range, $N S$ non-significant, $C R C$ colorectal cancer specificity were $54.8 \%$ and $76.8 \%$, respectively, for a cutoff CRP value of $116 \mathrm{mg} / \mathrm{L}$. AUCs for the ROC curves for gastrointestinal complications (either anastomotic leakage, bowel ischemia/necrosis, or perforation) against CRP values on PODs 3 and 4 were 0.71 (95\% CI $0.54-0.87$; $p=0.01)$ and $0.76(95 \% \mathrm{CI} 0.58-0.93 ; p=0.01)$ respectively (Fig. 2c, d). The cut-off CRP value at POD 3 was $188 \mathrm{mg} / \mathrm{L}$, with a sensitivity of $61.5 \%$ and specificity of $81.7 \%$ (Fig. 2c). At POD 4, CRP $\geq 160.5 \mathrm{mg} / \mathrm{L}$ had a sensitivity for a gastrointestinal complication of $66.7 \%$ and a specificity of $82.1 \%$. We also examined whether the CRP levels on PODs 3 and 4 can predict an intra-abdominal abscess (Figs. 2e, f). The AUCs for the ROC curves for CRP values on PODs 3 and 4 were $0.75(95 \%$ CI $0.60-0.90 ; p=0.002)$ and $0.61 \quad(95 \%$ CI $0.44-0.79$; $p=0.179)$, respectively. The cut-off CRP level on POD 3 was $166 \mathrm{mg} / \mathrm{L}$, with a sensitivity of $71.4 \%$ and specificity of $77.6 \%$.

Figure 3 demonstrates poor diagnostic accuracy of postoperative WBC levels on POD 3 (AUC $0.56,95 \%$ CI $0.45-0.68 ; p=0.25$ ) and POD 4 (AUC $0.60,95 \%$ CI $0.47-0.73 ; p=0.14)$ in detecting patients with SAE grade $\geq 3$ complications (Figs. 3a, b) and intra-abdominal abscesses (Figs. 3e, f). In contrast, the discriminative properties of postoperative WBC levels on POD 4 (AUC $0.71,95 \%$ CI $0.54-0.88, p=0.031$ ) for detecting gastrointestinal complications (either anastomotic leakage, bowel ischemia/necrosis, or perforation) were greater (Figs. 3c, d). In addition, a cut-off WBC level of $11.9 * 10^{9} /$ $\mathrm{L}$ was determined, with a sensitivity and specificity of $60 \%$ and $82.1 \%$, respectively.

\section{DISCUSSION}

The aim of this retrospective study was to determine the value of early postoperative inflammatory biomarker levels in identifying patients at risk of developing high-grade SAEs (SAE grade $\geq 3$ ) following CRS-HIPEC. To our knowledge, this is the first study to consider postoperative CRP and WBC levels as a diagnostic tool for identifying high-grade complications following CRS-HIPEC in patients with CRC, appendiceal cancer, and PMP. In cases of $\mathrm{SAE}$ grade $<3$ complications, CRP concentrations peaked on POD 2, and peaked at POD 3 in patients with 
TABLE 2 Intraoperative characteristics

\begin{tabular}{|c|c|c|c|c|}
\hline & $\begin{array}{l}\text { All procedures } \\
{[N=184]}\end{array}$ & $\begin{array}{l}\mathrm{SAE}<3 \\
{[n=134]}\end{array}$ & $\begin{array}{l}\mathrm{SAE} \geq 3 \\
{[n=50]}\end{array}$ & $p$ value \\
\hline $\mathrm{PCI}^{\mathrm{a}}$ & $10[6-16]$ & 10 [5-16] & $14[8-16]$ & NS \\
\hline \multicolumn{5}{|l|}{ (Partially) resected organs } \\
\hline Omentum & 174 (94.6) & $128(95.5)$ & $46(94)$ & NS \\
\hline Spleen & $12(6.5)$ & $6(4.5)$ & $6(12)$ & NS \\
\hline Urether & $5(2.7)$ & $3(2.2)$ & $2(4)$ & NS \\
\hline Bladder & $4(2.2)$ & $4(3)$ & 0 & NS \\
\hline Uterus $^{\mathrm{b}}$ & $36(39.6)$ & $28(20.9)$ & $8(16)$ & NS \\
\hline Ovaries $^{b}$ & $63(69.2)$ & $48(35.8)$ & $14(28)$ & NS \\
\hline Stomach & $2(1.1)$ & $1(0.7)$ & $1(2)$ & NS \\
\hline Liver & $10(5.4)$ & $7(5.2)$ & $3(6)$ & NS \\
\hline Pancreas & $11(6)$ & $7(5.2)$ & $4(8)$ & NS \\
\hline Gallbladder & $12(6.5)$ & $4(3)$ & $8(16)$ & 0.004 \\
\hline Duodenum & $10(5.4)$ & $4(3)$ & $1(2)$ & NS \\
\hline Small intestine & $52(28.3)$ & $35(26.1)$ & $17(34)$ & NS \\
\hline Appendix & $10(5.4)$ & $7(5.2)$ & $3(6)$ & NS \\
\hline Ileocecal & $22(12)$ & $13(9.7)$ & $9(18)$ & NS \\
\hline Ascending colon & $40(21.7)$ & $27(20.1)$ & $13(26)$ & NS \\
\hline Transverse colon & $21(11.4)$ & $12(9)$ & $9(18)$ & NS \\
\hline Descending colon & $12(6.5)$ & $9(6.7)$ & $3(6)$ & NS \\
\hline Sigmoid colon & $55(29.9)$ & $39(29.1)$ & $16(32)$ & NS \\
\hline Rectum & $47(25.5)$ & $32(23.9)$ & $15(30)$ & NS \\
\hline \multicolumn{5}{|l|}{ Diaphragm } \\
\hline Left & $20(10.9)$ & $14(10.4)$ & $6(12)$ & NS \\
\hline Right & $42(22.8)$ & $27(20.1)$ & $15(30)$ & NS \\
\hline \multicolumn{5}{|l|}{ Peritoneum } \\
\hline Left & $59(32.1)$ & $43(32.1)$ & $16(32)$ & NS \\
\hline Right & $73(39.7)$ & $52(38.8)$ & $21(42)$ & NS \\
\hline Pelvic & $71(38.6)$ & $57(42.5)$ & $14(28)$ & NS \\
\hline CCR score & & & & NS \\
\hline $\mathrm{R} 1$ & $177(96.2)$ & $130(97)$ & $47(94)$ & \\
\hline $\mathrm{R} 2 \mathrm{a}$ & $5(2.7)$ & $3(2.2)$ & $2(4)$ & \\
\hline $\mathrm{R} 2 \mathrm{~b}$ & $2(1.1)$ & $2(1.5)$ & 0 & \\
\hline Number of bowel anastomoses & & & & NS \\
\hline 0 & $75(40.8)$ & $60(44.8)$ & $15(30)$ & \\
\hline 1 & $86(46.7)$ & $62(46.3)$ & $24(48)$ & \\
\hline 2 & $17(9.2)$ & $8(6)$ & $9(18)$ & \\
\hline 3 & $4(2.2)$ & $2(1.5)$ & $2(4)$ & \\
\hline 4 & $2(1.1)$ & $2(1.5)$ & 0 & \\
\hline Stomy & & & & NS \\
\hline Ileostomy & $11(6)$ & $7(5.2)$ & $4(8)$ & \\
\hline Colostomy & $61(33.2)$ & $44(32.8)$ & $17(34)$ & \\
\hline Double barrel colostomy & $2(1.1)$ & $2(1.5)$ & 0 & \\
\hline HIPEC regimen & & & & NS \\
\hline Mitomycin-C & $164(89.1)$ & $121(90.3)$ & $43(86)$ & \\
\hline Oxaliplatin (5-fluorouracil, leucovorin) & $11(6)$ & $9(6.7)$ & $2(4)$ & \\
\hline Other & $9(4.9)$ & $5(3.7)$ & $4(8)$ & \\
\hline
\end{tabular}


TABLE 2 continued

\begin{tabular}{|c|c|c|c|c|}
\hline & $\begin{array}{l}\text { All procedures } \\
{[N=184]}\end{array}$ & $\begin{array}{l}\mathrm{SAE}<3 \\
{[n=134]}\end{array}$ & $\begin{array}{l}\mathrm{SAE} \geq 3 \\
{[n=50]}\end{array}$ & $p$ value \\
\hline Blood loss, mL & 1183 [714-2075] & 1063 [688-1763] & 1533 [900-2700] & 0.005 \\
\hline Procedure time, $\min$ & 398 [327-475] & 396 [326-454] & 399 [325-515] & NS \\
\hline
\end{tabular}

Continuous variables are reported as median [IQR], and proportions are reported as $n(\%)$

$S A E$ serious adverse event, $P C I$ Peritoneal Cancer Index, $C C R$ completeness of cytoreduction, IQR interquartile range, $N S$ non-significant, $C R S$ HIPEC cytoreductive surgery-hyperthermic intraperitoneal chemotherapy

${ }^{a}$ Applicable to CRS-HIPEC procedures for colorectal cancer $(n=147)$

${ }^{\mathrm{b}}$ Proportion of CRS-HIPEC procedures in female patients $(n=91)$

TABLE 3 Postoperative course

\begin{tabular}{|c|c|c|c|}
\hline & $\begin{array}{l}\text { All procedures } \\
{[N=184]}\end{array}$ & $\begin{array}{l}\mathrm{SAE}<3 \\
{[n=134]}\end{array}$ & $\begin{array}{l}\mathrm{SAE} \geq 3 \\
{[n=50]}\end{array}$ \\
\hline \multicolumn{4}{|l|}{ Complications } \\
\hline Intra-abdominal bleeding & $7(3.8)$ & $1(0.7)$ & $6(12)$ \\
\hline Anastomotic leakage $^{a}$ & $9(4.9)$ & 0 & $9(18)$ \\
\hline Bowel perforation/ischemia & $9(4.9)$ & 0 & $9(18)$ \\
\hline Wound dehiscence & $5(2.7)$ & $1(0.7)$ & $4(8)$ \\
\hline Intra-abdominal abscess & $21(11.4)$ & $3(2.2)$ & $18(36)$ \\
\hline Wound infection & $20(10.9)$ & $15(11.2)$ & $5(10)$ \\
\hline UTI & $16(8.7)$ & $14(10.4)$ & $2(4)$ \\
\hline Pneumonia & $8(4.3)$ & $6(4.5)$ & $2(4)$ \\
\hline Pulmonary embolism & $7(3.8)$ & $2(1.5)$ & $5(10)$ \\
\hline SAE grade & & - & - \\
\hline 0 & $58(31.5)$ & & \\
\hline 1 & $29(15.8)$ & & \\
\hline 2 & $46(25)$ & & \\
\hline 3 & $24(13)$ & & \\
\hline 4 & $20(10.9)$ & & \\
\hline 5 & $6(3.3)$ & & \\
\hline Reoperation & $28(15.2)$ & 0 & $28(56)$ \\
\hline ICU stay & $3[2-3]$ & $3[2-3]$ & $4[3-8]$ \\
\hline Hospital stay & 17 [13-23] & $15.5[12-18.3]$ & 30 [19-39] \\
\hline In-hospital mortality & $6(3.3)$ & 0 & $6(12)$ \\
\hline
\end{tabular}

Continuous variables are reported as median [IQR], and proportions are reported as $n(\%)$

$S A E$ serious adverse event, UTI urinary tract infection, ICU intensive care unit, IQR interquartile range, $C R S$-HIPEC cytoreductive surgery-hyperthermic intraperitoneal chemotherapy

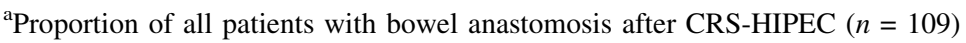

SAE $\geq 3$ complications. The differences in CRP concentrations were significant from POD 2 until POD 5 between the aforementioned two groups. Most (78\%) postoperative $\mathrm{SAE} \geq 3$ complications were diagnosed after peak CRP concentrations.

In this study, POD 3 and POD 4 were chosen as the time points for calculating AUCs, considering the compelling research ${ }^{20}$ that suggests that postoperative CRP reaches a peak at POD 3 or 4 , with better predictive accuracy than
CRP on PODs 1 or 2. CRP values on POD 3 had moderate diagnostic accuracy (AUCs $>0.70$ ) for predicting SAE $\geq 3$, with cut-off values of $166 \mathrm{mg} / \mathrm{L}$ on POD 3 (sensitivity $61.1 \%$; specificity $84.5 \%$ ). Gans et al. ${ }^{20}$ reported a similar CRP cut-off value of $159 \mathrm{mg} / \mathrm{L}$ on POD 3 (sensitivity $77 \%$; specificity $77 \%$ ) in a meta-analysis regarding 'major abdominal surgery'. The data observed in our tertiary center suggest that high CRP levels on PODs 3 and 4 indicate a considerable risk for developing high-grade 
FIG. 1 a Postoperative CRP values after CRS and HIPEC. b Postoperative WBC count after CRS and HIPEC. POD postoperative day, $C R P$ C-reactive protein, $S A E$ serious adverse event, $W B C$ white blood cell count

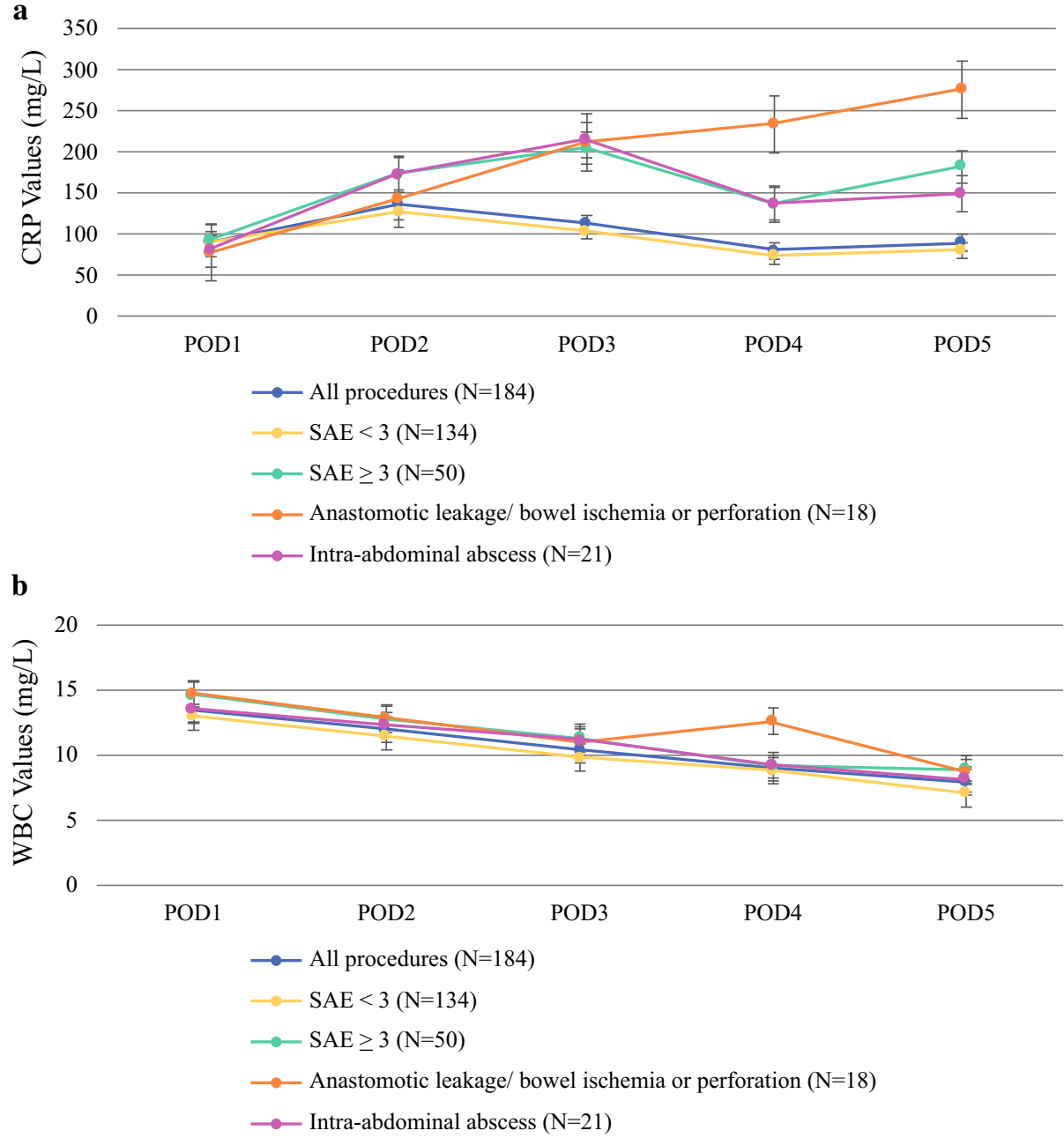

SAEs (i.e. SAE grade $\geq 3$ ). In addition, considering the peak in CRP levels at POD 2 in patients not developing high-grade SAEs versus the peak at POD 3 in patients who do develop high-grade SAEs, clinicians should be extra cautious if CRP levels keep rising after POD 2, especially when they exceed the aforementioned cut-off levels at PODs 3 and 4. These cut-off CRP values may potentially be set as thresholds for additional (abdominal) imaging. External validation should be performed before incorporating this in routine clinical practice.

These aforementioned results suggest that CRP might be utilized to identify patients who are at high risk of developing postoperative $\mathrm{SAE} \geq 3$ complications. In clinical practice, besides CRP, other variables such as heart rate, temperature, blood pressure, and urinary output are taken into account in decision making for further diagnostics or a reoperation. Taking the inexpensiveness of the laboratory test into account (less than $€ 4$ in The Netherlands), also makes this biomarker even more attractive for postoperative monitoring. The current study exclusively analyzed CRP levels and did not consider other clinical parameters. These clinical parameters can influence the pretest probability of developing high-grade SAEs, thereby improving the predictive value of CRP. Hence, if CRP levels are $\geq 166$ at POD 3 , clinicians might pay better attention to other clinical parameters. Consequently, the early detection rate of high-grade SAEs might increase.

Unfortunately, it was not possible to predict specific complications based on CRP levels alone. Although CRP levels were significantly increased in patients who developed intra-abdominal abscesses or gastrointestinal leakage, the predictive value of CRP for these specific complications was low. This can be explained first by the fact that CRP is a non-specific biomarker and therefore the predictive ability for specific complications is low. Second, the number of events per complication was too small for conclusive statistical analysis; thus, elevated CRP can increase caution for the high possibility that serious complications are evolving, but it cannot precisely predict what complication will develop. 
FIG. 2 a-f Receiver operating characteristic curve for C-reactive protein. $\mathrm{SAE} \geq 3$ at a POD 3 and b POD4; gastrointestinal complications at c POD 3 and d POD 4; intraabdominal abscess at e POD 3 and $\mathbf{f}$ POD 4. AUC area under the receiver operating characteristic curve, $S A E$ serious adverse event, $P O D$ postoperative day
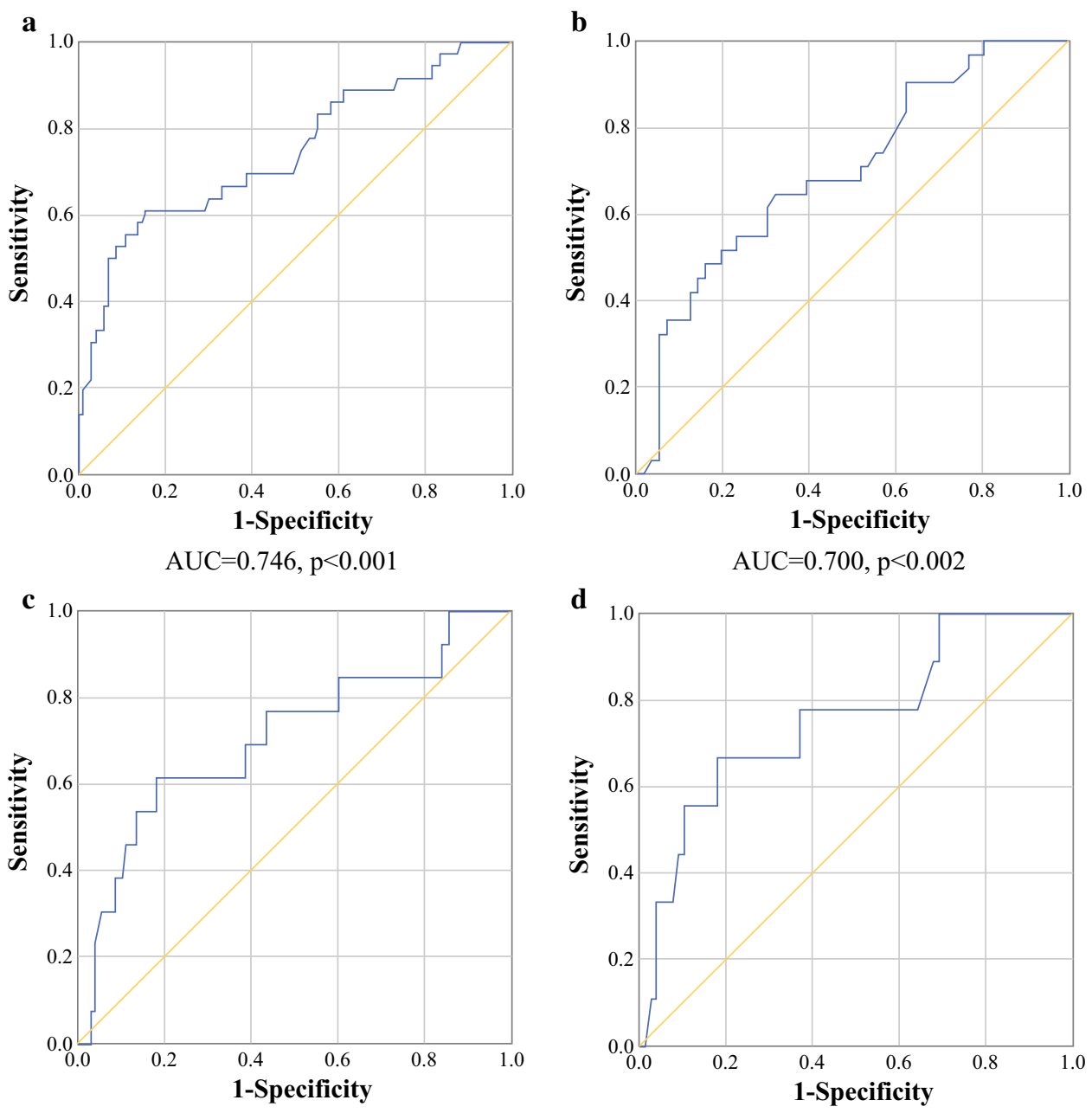

$\mathrm{AUC}=0.708, \mathrm{p}<0.014$

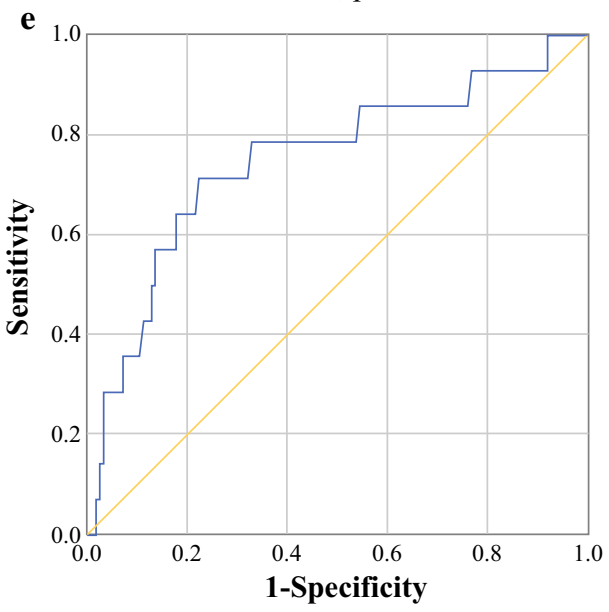

$\mathrm{AUC}=0.751, \mathrm{p}<0.002$

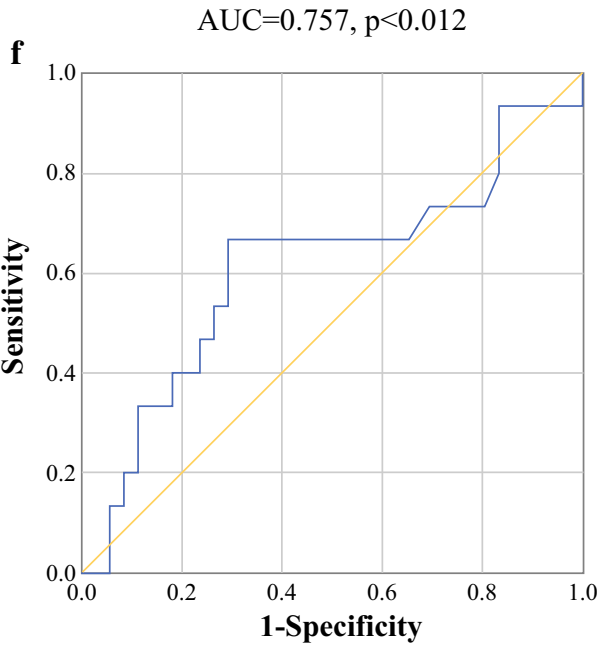

AUC $=0.611, p<0.179$
WBC count did not differ significantly between the $\mathrm{SAE}<3$ and $\mathrm{SAE} \geq 3$ groups; however, a significant increase in WBC levels from POD 3 to POD 4 was observed in patients with gastrointestinal complications, with a corresponding ROC curve demonstrating moderate diagnostic accuracy. Nonetheless, WBC appears to be less useful, in general, than CRP for detecting high-grade SAEs. A possible explanation might be the low WBC levels due to extensive blood loss and dilution from intravenous fluid administration after CRS-HIPEC. Studies 
FIG. 3 a-f Receiver operating characteristic curves for white blood cell count. SAE $\geq 3$ at a POD 3 and b POD 4; gastrointestinal complications at c POD 3 and d POD 4; intraabdominal abscess at e POD 3 and (f) POD 4. AUC area under the receiver operating characteristic curve, $S A E$ serious adverse event, $P O D$ postoperative day
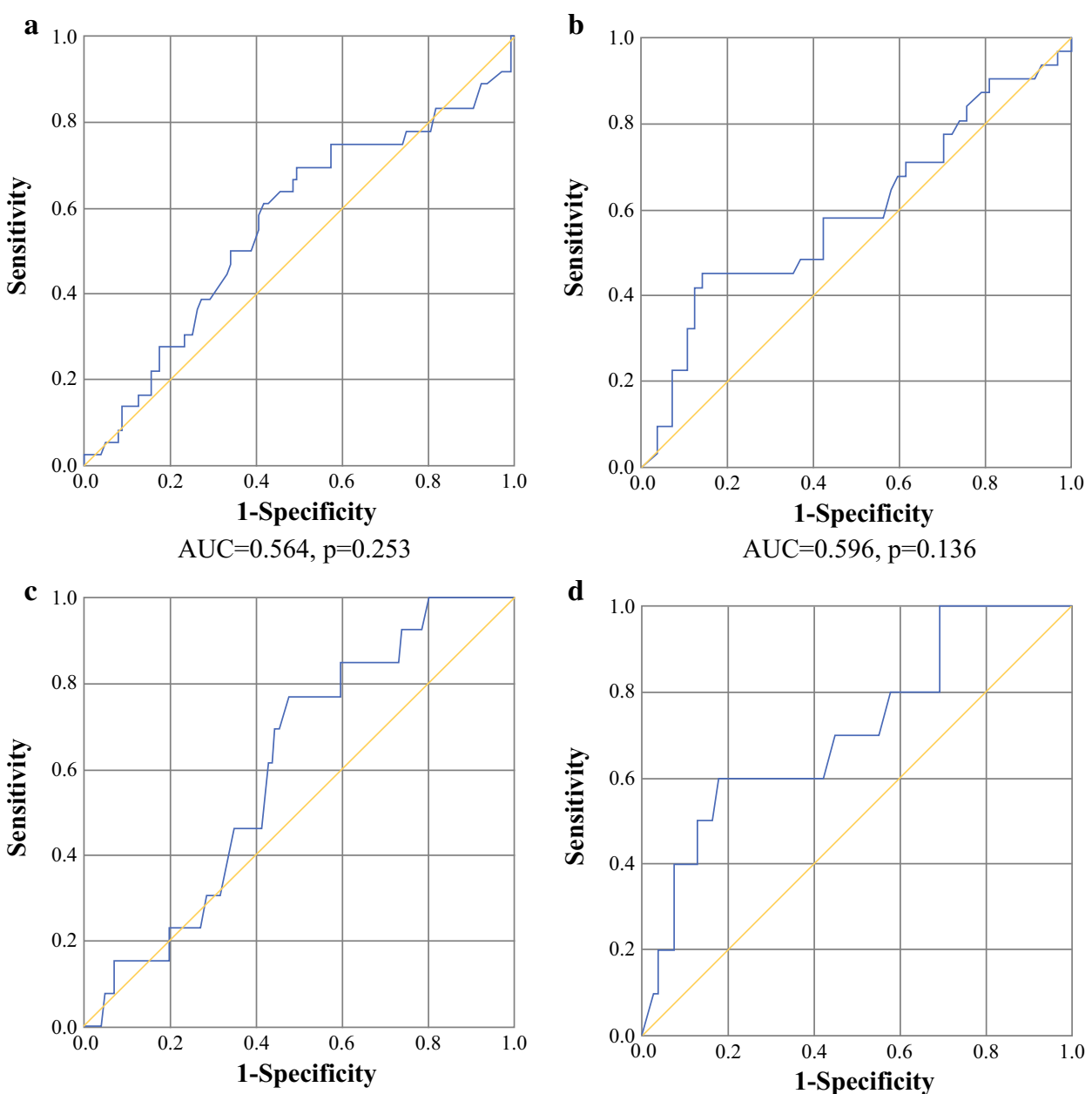

$\mathrm{AUC}=0.606, \mathrm{p}=0.211$

d
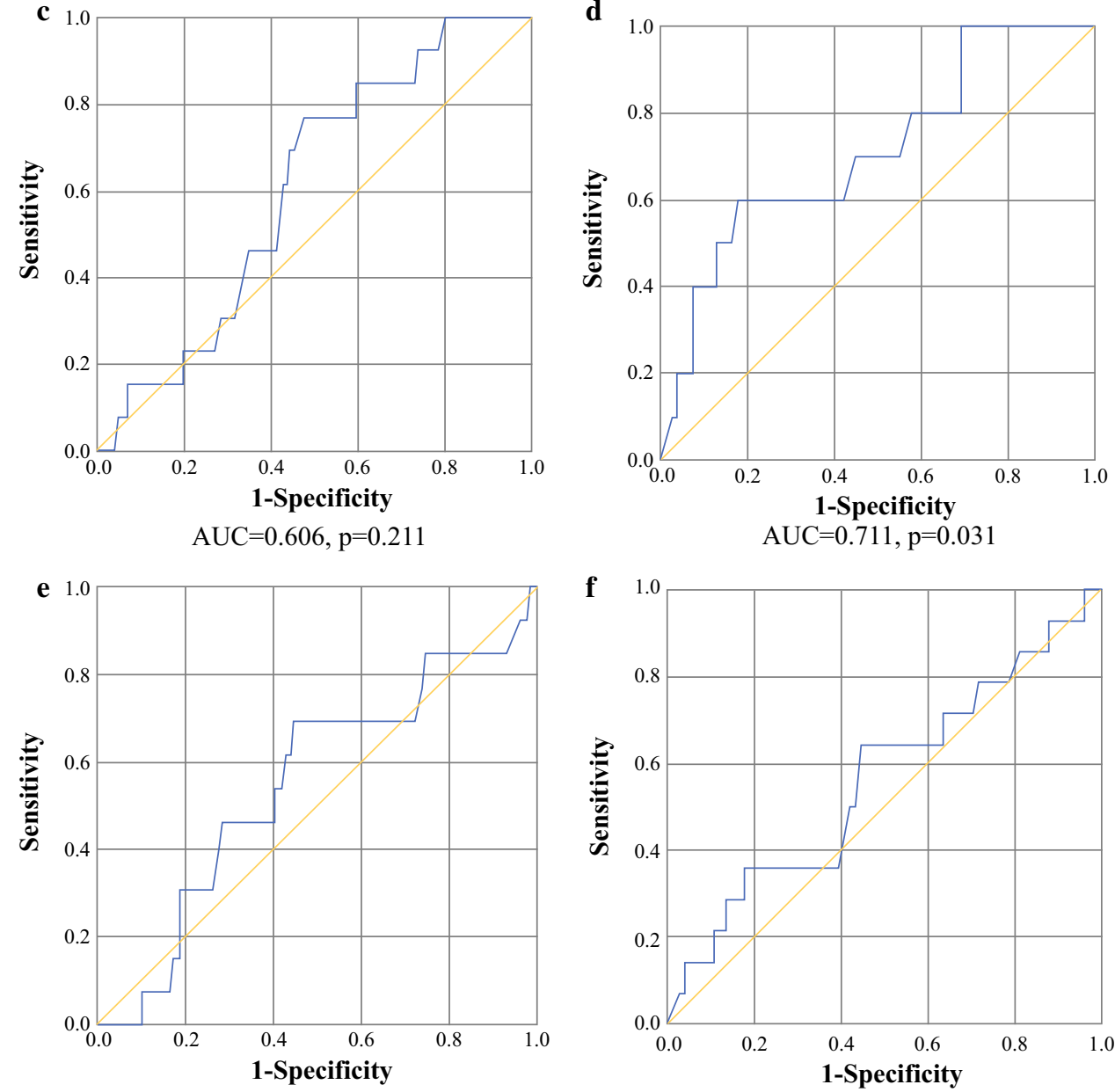

$\mathrm{AUC}=0.548, \mathrm{p}=0.568$

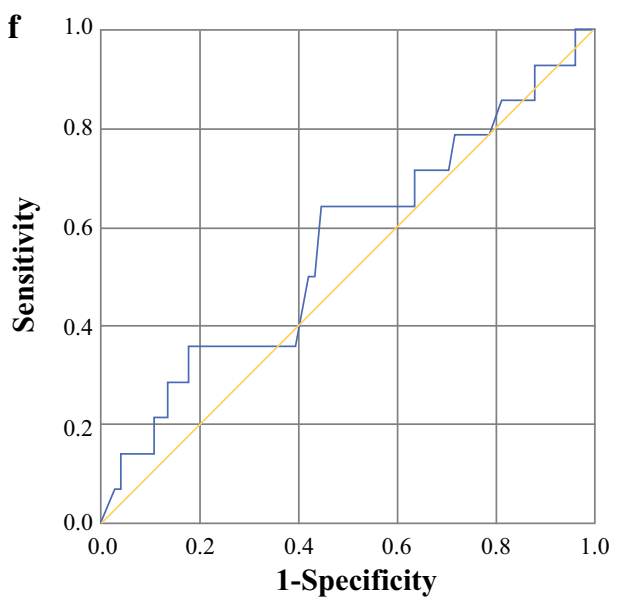

$\mathrm{AUC}=0.561, \mathrm{p}=0.469$ have also shown suppression of the cellular immune response after major surgery, trauma, or injury. ${ }^{21,22}$ For CRS-HIPEC procedures specifically, mild leukopenia has been reported as a result of systemic uptake of intraperitoneal chemotherapy. ${ }^{23,24}$ These reasons might explain why WBC does not seem to be a reliable predictor of early postoperative complications in patients undergoing CRSHIPEC. This observation has been previously reported for colorectal surgery. ${ }^{25}$

The current study found significant differences between the $\mathrm{SAE}<3$ and $\mathrm{SAE} \geq 3$ groups in relation to sex, number of cholecystectomies, and blood loss. In previously 
published literature, the effect of sex on postoperative outcomes has been debated. Some earlier studies demonstrated that male patients have a higher risk of complications following colorectal surgery (open and laparoscopic), ${ }^{26}$ and that higher rates of anastomotic leakages were associated with male sex. ${ }^{27}$ However, these aforementioned associations with sex have not been demonstrated in other (retrospective) cohort studies of patients undergoing CRS and HIPEC. ${ }^{28-30}$ In the current data, no explanation could be found for this observation. In the $\mathrm{SAE} \geq 3$ group, significantly more cholecystectomies were performed during CRS. Cholecystectomy has not been earlier described as a risk factor for developing highgrade SAEs after CRS and HIPEC. As most of the cholecystectomies were performed in patients with PMPs, it is very likely that cholecystectomy is an indicator of the extent of disease spread, and thus the extent of surgery. The significant difference in the proportion of cholecystectomies between the $\mathrm{SAE}<3$ and $\mathrm{SAE} \geq 3$ groups may be explained via this underlying mechanism. Lastly, median blood loss was significantly higher in the $\mathrm{SAE} \geq 3$ group. This observation was expected as extensive blood loss has been associated with postoperative morbidity in both general colorectal surgery and the CRS and HIPEC procedures. ${ }^{26,31,32}$ Perioperative blood loss may, to some extent, reflect the extensiveness of the procedure; there will generally be more blood loss in larger procedures, which results in an increased risk of developing high-grade SAEs. ${ }^{28-30}$

\section{Limitations}

There are some limitations to the current study, including, first, the retrospective nature of data collection (including laboratory markers) and the limited study sample size, and, second, the amount of (possibly non-random) missing laboratory data, particularly on POD 4. This is explained by the postoperative HIPEC protocol in the Erasmus MC, which states that laboratory testing should be performed daily on the first, second, and third PODs, and afterwards three times per week on the ward. Third, only the 'early' (until POD 5) CRP levels were analyzed in this study, since most CRP values after POD 5 were more likely to be 'missing not at random': missingness related to a speedy recovery, and thus unnecessary laboratory testing and/or hospital discharge ('confounding by indication'). However, this observation was not considered an issue for this particular study, considering its aim was to evaluate $\mathrm{CRP}$ as a biomarker for early detection of $\mathrm{SAE} \geq 3$ complications. In addition, Medina Fernandez et al. ${ }^{16}$ suggested that CRP cut-off values might only be of value in the first postoperative week, as their results found CRP levels in the second postoperative week to be not significantly different between patients who developed infectious complications and those who did not, following CRS-HIPEC for ovarian PC.

\section{CONCLUSION}

With a cut-off value of $166 \mathrm{mg} / \mathrm{L}$ on POD 3 after CRSHIPEC, CRP is a good screening test with high specificity in differentiating between $\mathrm{SAE}<3$ and $\mathrm{SAE} \geq 3$ complications. Following CRS-HIPEC, postoperative CRP levels might not only aid in patient selection to prevent overuse of imaging but also for earlier and safe hospital discharge. More prospective studies are needed to more accurately determine the predictive ability of early postoperative CRP levels, in combination with clinical parameters, after CRS-HIPEC.

DISCLOSURES Job P. van Kooten, Arvind Oemrawsingh, Nadine L. de Boer, Cornelis Verhoef, Jacobus W.A. Burger, Eva V.E. Madsen, and Alexandra R.M. Brandt-Kerkhof have no conflicts of interest to declare.

OPEN ACCESS This article is licensed under a Creative Commons Attribution 4.0 International License, which permits use, sharing, adaptation, distribution and reproduction in any medium or format, as long as you give appropriate credit to the original author(s) and the source, provide a link to the Creative Commons licence, and indicate if changes were made. The images or other third party material in this article are included in the article's Creative Commons licence, unless indicated otherwise in a credit line to the material. If material is not included in the article's Creative Commons licence and your intended use is not permitted by statutory regulation or exceeds the permitted use, you will need to obtain permission directly from the copyright holder. To view a copy of this licence, visit http://creativecommons. org/licenses/by/4.0/.

\section{REFERENCES}

1. Glehen O, Gilly FN, Boutitie F, et al. Toward curative treatment of peritoneal carcinomatosis from nonovarian origin by cytoreductive surgery combined with perioperative intraperitoneal chemotherapy: a multi-institutional study of 1,290 patients. Cancer. 2010;116(24):5608-618.

2. Maggiori L, Elias D. Curative treatment of colorectal peritoneal carcinomatosis: current status and future trends. Eur J Surg Oncol. 2010;36(7):599-603.

3. Verwaal VJ, Bruin S, Boot H, van Slooten G, van Tinteren H. 8-year follow-up of randomized trial: cytoreduction and hyperthermic intraperitoneal chemotherapy versus systemic chemotherapy in patients with peritoneal carcinomatosis of colorectal cancer. Ann Surg Oncol. 2008;15(9):2426-432.

4. Chua TC, Moran BJ, Sugarbaker PH, et al. Early- and long-term outcome data of patients with pseudomyxoma peritonei from appendiceal origin treated by a strategy of cytoreductive surgery and hyperthermic intraperitoneal chemotherapy. J Clin Oncol. 2012;30(20):2449-456.

5. Levine EA, Stewart JH 4th, Shen P, Russell GB, Loggie BL, Votanopoulos KI. Intraperitoneal chemotherapy for peritoneal 
surface malignancy: experience with 1,000 patients. $J$ Am Coll Surg. 2014;218(4):573-85.

6. Huang CQ, Min Y, Wang SY, et al. Cytoreductive surgery plus hyperthermic intraperitoneal chemotherapy improves survival for peritoneal carcinomatosis from colorectal cancer: a systematic review and meta-analysis of current evidence. Oncotarget. 2017;8(33):55657-5683.

7. Bartlett EK, Meise C, Roses RE, Fraker DL, Kelz RR, Karakousis GC. Morbidity and mortality of cytoreduction with intraperitoneal chemotherapy: outcomes from the ACS NSQIP database. Ann Surg Oncol. 2014;21(5):1494-500.

8. Jafari MD, Halabi WJ, Stamos MJ, et al. Surgical outcomes of hyperthermic intraperitoneal chemotherapy: analysis of the American College of Surgeons National Surgical Quality Improvement Program. JAMA Surg. 2014;149(2):170-75.

9. Peters MG, Bartlett EK, Roses RE, Kelz RR, Fraker DL, Karakousis GC. Age-related morbidity and mortality with cytoreductive surgery. Ann Surg Oncol. 2015;22 Suppl 3:S898S904.

10. $\mathrm{Du}$ Clos TW. Function of C-reactive protein. Ann Med. 2000;32(4):274-278.

11. Pierrakos C, Vincent JL. Sepsis biomarkers: a review. Criti Care. 2010;14(1):R15.

12. Hoeboer SH, Groeneveld AB, Engels N, van Genderen M, Wijnhoven BP, van Bommel J. Rising C-reactive protein and procalcitonin levels precede early complications after esophagectomy. J Gastrointest Surg. 2015;19(4):613-24.

13. MacKay GJ, Molloy RG, O'Dwyer PJ. C-reactive protein as a predictor of postoperative infective complications following elective colorectal resection. Color Dis. 2011;13(5):583-587.

14. Ortega-Deballon P, Radais F, Facy O, et al. C-reactive protein is an early predictor of septic complications after elective colorectal surgery. World J Surg. 2010;34(4):808-814.

15. Sparreboom CL, Wu ZQ, Ji JF, Lange JF. Integrated approach to colorectal anastomotic leakage: communication, infection and healing disturbances. World $J$ Gastroenterol. 2016;22(32):7226-235.

16. Medina Fernandez FJ, Munoz-Casares FC, Arjona-Sanchez A, et al. Postoperative time course and utility of inflammatory markers in patients with ovarian peritoneal carcinomatosis treated with neoadjuvant chemotherapy, cytoreductive surgery, and HIPEC. Ann Surg Oncol. 2015;22(4):1332-340.

17. Kuijpers AM, Mirck B, Aalbers AG, et al. Cytoreduction and HIPEC in the Netherlands: nationwide long-term outcome following the Dutch protocol. Annals of surgical oncology. 2013;20(13):4224-4230.

18. Jacquet P, Sugarbaker PH. Clinical research methodologies in diagnosis and staging of patients with peritoneal carcinomatosis. Cancer Treat Rese. 1996;82:359-374.

19. Trotti A, Colevas AD, Setser A, et al. CTCAE v30: development of a comprehensive grading system for the adverse effects of cancer treatment. Semin Radiat Oncol. 2003;13(3):176-181.

20. Gans SL, Atema JJ, van Dieren S, Groot Koerkamp B, Boermeester MA. Diagnostic value of C-reactive protein to rule out infectious complications after major abdominal surgery: a systematic review and meta-analysis. Int $J$ Colorectal Dis. 2015;30(7):861-873.
21. Kimura F, Shimizu H, Yoshidome H, Ohtsuka M, Miyazaki M. Immunosuppression following surgical and traumatic injury. Surg Today. 2010;40(9):793-808.

22. Franke A, Lante W, Kurig E, Zoller LG, Weinhold C, Markewitz A. Hyporesponsiveness of $\mathrm{T}$ cell subsets after cardiac surgery: a product of altered cell function or merely a result of absolute cell count changes in peripheral blood? Eur J Cardiothorac Surg. 2006;30(1):64-71.

23. Hakeam HA, Arab A, Azzam A, Alyahya Z, Eldali AM, Amin T. Incidence of leukopenia and thrombocytopenia with cisplatin plus mitomycin-c versus melphalan in patients undergoing cytoreductive surgery (CRS) and hyperthermic intraperitoneal chemotherapy (HIPEC). Cancer Chemother Pharmacol. 2018;81(4):697-704.

24. Horvath P, Beckert S, Struller F, Konigsrainer A, Konigsrainer I. Incidence of leukopenia after intraperitoneal vs combined intravenous/intraperitoneal chemotherapy in pseudomyxoma peritonei. World $J$ Gastrointest Pharmacol Ther. 2016;7(3):434-39.

25. Warschkow R, Tarantino I, Torzewski M, Naf F, Lange J, Steffen T. Diagnostic accuracy of C-reactive protein and white blood cell counts in the early detection of inflammatory complications after open resection of colorectal cancer: a retrospective study of 1,187 patients. Int J Colorectal Dis. 2011;26(11):1405-1413.

26. Kirchhoff P, Clavien PA, Hahnloser D. Complications in colorectal surgery: risk factors and preventive strategies. Patient Saf Surg. 2010;4(1):5.

27. Lipska MA, Bissett IP, Parry BR, Merrie AE. Anastomotic leakage after lower gastrointestinal anastomosis: men are at a higher risk. ANZ J Surg. 2006;76(7):579-85.

28. Stephens AD, Alderman R, Chang D, et al. Morbidity and mortality analysis of 200 treatments with cytoreductive surgery and hyperthermic intraoperative intraperitoneal chemotherapy using the coliseum technique. Ann Surg Oncol. 1999;6(8):790-796.

29. Yan TD, Zappa L, Edwards G, Alderman R, Marquardt CE, Sugarbaker PH. Perioperative outcomes of cytoreductive surgery and perioperative intraperitoneal chemotherapy for non-appendiceal peritoneal carcinomatosis from a prospective database. $J$ Surg Oncol. 2007;96(2):102-112.

30. Glehen O, Osinsky D, Cotte E, et al. Intraperitoneal chemohyperthermia using a closed abdominal procedure and cytoreductive surgery for the treatment of peritoneal carcinomatosis: morbidity and mortality analysis of 216 consecutive procedures. Ann Surg Oncol. 2003;10(8):863-69.

31. Mizumoto A, Canbay E, Hirano M, et al. Morbidity and mortality outcomes of cytoreductive surgery and hyperthermic intraperitoneal chemotherapy at a single institution in Japan. Gastroenterol Res Pract. 2012;2012:836425.

32. Cardi M, Sibio S, Di Marzo F, et al. Prognostic factors influencing infectious complications after cytoreductive surgery and HIPEC: results from a tertiary referral center. Gastroenterol Res Pract. 2019;2019:2824073.

Publisher's Note Springer Nature remains neutral with regard to jurisdictional claims in published maps and institutional affiliations. 